\title{
C. Ursul
}

\section{La categoría gramatical de la modalidad en el idioma español: base cognitiva}

\author{
Cristina Ursul, Doctora en Filología, Profesora adjunta \\ del Depto. de Teoría y Práctica de Interpretación y Traducción \\ de la Universidad Estatal Humanitaria de Rusia, Moscú. \\ ursul-16@mail.ru
}

\begin{abstract}
Resumen. El artículo está dedicado a la categoría gramatical de la modalidad en el español moderno. La autora utiliza un enfoque semántico funcional para analizar detalladamente la estructura de la categoría gramatical de la modalidad en el español e identificar sus fundamentos conceptuales. Se analiza la organización estructural de la categoría gramatical de la modalidad en el idioma español y se revela su base cognitiva con el fin de formar una representación esquemática de esta categoría, lo que en el futuro contribuirá a la solución del problema de la cantidad de los modos en el español moderno para evitar una serie de errores en las traducciones del ruso al español y al revés. También la autora introduce como parte de la investigación el término "campo de tiempo». El «campo del tiempo» se refiere a la mente mientras que la categoría gramatical del tiempo, directamente al idioma. La correlación de estos dos términos hace posible visualizar la conexión de la mente humana con el lenguaje y configurar tres modos diferentes, es decir el Indicativo, el Subjuntivo, el Imperativo.
\end{abstract}

Palabras claves: enfogue semántico funcional, modalidad, concepto, modo, ciencia cognitiva.

\section{Cristina Ursul}

\section{Grammar category of modality in Spanish: cognitive bases}

\begin{abstract}
The article deals with the grammar category of modality in the structure of modern Spanish. The author aims to analyze the structural organization of the grammar category of modality in the Spanish language and to reveal its cognitive bases in order to form a schematic representation of this category, which in the future will allow, first of all, to solve the problem of the number of moods in modern Spanish, and also to avoid some mistakes when translating sentences from Russian into Spanish, and from Spanish into Russian as well. The usage of a functionalsemantic approach helps to analyze in details the structure of the grammar category of modality in the language and to educe its conceptual bases. Within a framework of the study the author introduces the term "field of time". The "field of time" refers to the mentality, while the grammar category of time - to a language. The correlation of these terms facilitates to visualize the connection of the way of thinking with a language and to separate three different moods in the Spanish language, that are el Indicativo, el Subjuntivo, el Imperativo.
\end{abstract}

Key words: functional-semantic approach, modality, concept, mood, cognitive science. 


\title{
К. В. Урсул
}

\section{Грамматическая категория модальности в испанском языке: когнитивные основания}

\begin{abstract}
Аннопация. Спапья посвящена граммапичесkой kапегории модальноспи в современном испанском языkе. Авпор используеп функционально-семанпический подход Аля депального анализа спруkпypbl граммапичесkой kaпегории модальноспи на испансkом языke и выляления её концеппуальных основ. Анализируепся спруkпурная организация граммапичеckoӥ капегории модальноспи в испанском языke и расkpbıваепся её когнипивная база Аля формирования подробного описания эпой капегории, чпо в будущем будеп способспвовапь решению проблемbl количеспва наkлонений в современном испансkом язbıke. Эпо позволип избежаmb ряда ошибок при переводе с русckoго на испансkий и наобороп. Авпор паkже вводип пермин «поле времени» kak часпь исследования. «Поле времени» опносипся k разуму, а граммапичеckaя капегория времени - непосредспвенно k языky. Соопношение эпих Авух перминов позволяеп визуализировапь связь человеческого разума с языком и разграничипь при испанских наклонения, а именно: индикапивное, сослагапельное и повелипельное.
\end{abstract}

Ключевbе слова: Функционально-семанпический подход, модальноспь, концепп, наклонение, когнипивная науkа.

Actualmente casi todos los idiomas tienden a tener una sola lógica en cuanto a la construcción de la frase en la mente humana, aunque esto no quita posibles diferencias en las formas lingüísticas que la representan. T. A. Van Dijk afirma que los principales componentes de la teoría general de interacción comunicativa es la teoría cognitiva del uso del lenguaje [1]. El término "concepto" fue establecido como el básico en el marco de la concepción cognitiva.

El "concepto" como categoría filosófica universal principalmente se refiere a nuestros pensamientos, reflejando al mismo tiempo las características específicas de la gente que domina un idioma determinado.

La representación verbal de los conceptos básicos se lleva a cabo por medio de las categorías lógicas. En el proceso del pensamiento como fase superior del conocimiento humano, los conceptos básicos recorren una transformación y se materializan, lo que influye en la formación de las categorías que reflejan las cualidades y relaciones más comunes de alguna esfera de la realidad.

El contenido esencial de los conceptos en las operaciones mentales se convierte en las categorías semánticas conceptuales que encuentran su expresión en el lenguaje en forma de las categorías gramaticales.

La apelación a la ciencia cognitiva en este contexto ofrece la única oportunidad de identificar las bases conceptuales en la estructura del lenguaje y subrayar la base campal de las categorías lingüísticas.

Aplicando el enfoque semántico funcional con el fin de formar una representación esquemática de la categoría gramatical de modalidad, lo que en el futuro permitirá resolver el problema de cantidad de los modos en el español moderno y evitar una serie de errores en las traducciones del ruso al español y al revés, introducimos el término "campo de tiempo".

En este estudio científico nos basamos en los datos de la Real Academia Española y en el material de varias investigaciones de los lingüistas tanto rusos, como españoles.

El término "campo de tiempo" denota la categoría gramatical de tiempo. Sin embargo, diciendo "campo de tiempo" nos referimos a la zona de nuestra mente, mientras que la categoría de tiempo está directamente relacionada con el lenguaje, el discurso. La corelación de estas nociones nos permite visualizar la relación entre la mente y el lenguaje. El análisis semántico funcional actúa como un vínculo entre el lenguaje y el pensamiento. El término "semántico funcional" nos da razones de clasificar la categoría, de la que se trata en la investigación, como la que pertenece al lenguaje y a la mente a la vez.

En la estructura de la lengua española el campo de tiempo comprende un campo "semántico funcional de tiempo" y un campo "semántico funcional de modalidad", que junto con el complejo de varios niveles de los medios del idioma determinado encuentran su expresión lingüística en forma de la categoría gramatical de tiempo y la categoría gramatical de modalidad, respectivamente. 
La categoría gramatical de tiempo está vinculada con la categoría gramatical de modalidad, que es una proyección de la categoría semántica conceptual de modalidad. Esta categoría lógicamental se refiere a un grupo de categorías que actúan como la interface de nuestra mente.

O. Bochkova cree que la interpretación del término "modalidad" en la lingüística moderna es excepcionalmente amplia. La categoría de modalidad que expresa diferentes relaciones entre el hablante, el contenido de la frase dicha y la realidad en general, es el objeto de estudios de varias asignaturas relacionadas con: lógica, filosofía y lingüística. En la lingüística hasta el momento no existe la única definición de modalidad. La categoría de modalidad tiene raíces filosóficas. El Diccionario enciclopédico de filosofía define la modalidad como una forma de entender las sentencias de un objeto, fenómeno o evento dados. Es una categoría lógica porque se refiere a la sentencia. Este aspecto de lógica está directamente relacionado con la lingüística, es decir con la gramática [2].

En el Diccionario de términos lingüísticos de D. Rosental encontramos la siguiente definición de "modalidad": es la categoría semántica gramatical que expresa la actitud del hablante hacia lo dicho, su evaluación de lo dicho respecto a la realidad objetiva. El contenido de la frase puede ser pensado como real o irreal, posible o imposible, deseable o indeseable, etc. El sentido modal junto con el de tiempo constituye la categoría predicativa [3].

Teniéndolo en cuenta, en el marco del estudio la modalidad se entiende como una categoría semántica comprensiva, el proceso de la formación que se realiza en nuestra mente. Proyectando sobre la clase semántico-léxica de verbo, esta categoría con diferentes medios lingüísticos forma el campo semántico funcional de modalidad que en la lengua está representada en forma de la categoría gramatical de modalidad.

La modalidad como una categoría gramatical expresa la relación del hablante con la realidad. En los estudios actuales del hispanismo el problema de la cantidad de los modos en el español no lo han solucionado todavía. Por el momento, el número total de los modos en las lenguas de la Península Ibérica, y en el español en particular, no se emite en un número específico. Muchos estudios dedicados a este problema representan un análisis de las opiniones de diversos especialistas en esta esfera. Por el momento, ningún científico ha indicado una postura clara respecto al estado de algunas formas gramaticales (Imperativo y Condicional; ¿qué es esto, una forma temporal o un modo determinado?).

Por lo tanto, N. Ivanov define el modo verbal como una forma gramatical de la expresión de la modalidad lógica (V. Vinogradov). La modalidad modifica la función verdadera del lenguaje $<$... $>$ La modalidad verbal fortalece/debilita la función verdadera en la oración. La categoría de modalidad refleja una amplia gama de significados gramaticales que permiten describir el modelo del comportamiento cognitivo del sujeto [4, p. 393]. Con la ayuda de modalidad se puede expresar el estado real de las cosas.

No se molesta. / Sé valiente.

También esta categoría permite expresar el grado de posibilidad/probabilidad del evento.

Sé que escribe. / Dudo que escriba.

A. Anufriev cree que el sistema de los modos en las lenguas romances en general representa la oposición del Indicativo como el modo de la realidad y el Subjuntivo que expresa diferentes modus (el modus de deseo, necesidad y duda) [5, p. 150-152].

Sin embargo, la cuestión en cuanto al número total de los modos en el español moderno es una cierta complejidad, debido a un gran número de opiniones diferentes de los lingüistas.

N. Zenenko señala que en la gramática romance tradicionalmente se identifican cuatro modos: Indicativo, Subjuntivo, Imperativo, Condicional. A pesar de esto, se expresan diferentes opiniones con respecto al número de los modos que funcionan en las lenguas romances, y en el español en particular. Según algunos lingüistas, los científicos creen que el sistema de lenguas romances tiene cinco modos, es decir, Indicativo, Subjuntivo, Imperativo, Infinitivo y Condicional [6, p. 34-39]. En sus estudios lingüísticos, la autora señala que en la nomenclatura española se usan los términos Condicional Simple y Condicional Compuesto. M. Seco señala que aunque según la Real Academia Española el Condicional se considera como un modo, hoy ningún científico lo afirmará [Ibid., p. 35].

Para resolver el problema N. Zenenko se refiere al Diccionario de términos lingüísticos de O. Ajmanova, donde encuentra la siguiente interpretación de los términos Condicional o Potencial: es el modo optativo ..., contiene el sentido modal de probabilidad; también es el modo potencial, contiene el sentido potencial; es el modo condicional, es la forma del modo Subjuntivo, que se refiere a un proceso que en realidad no se realiza, pero que podría realizarse bajo ciertas condiciones [6, p. 36].

Como consecuencia, N. Zenenko, fijándose en definir lo que es - el modo o la forma verbal - señala que el sistema de los modos en el español implica no sólo su propia semántica (el Indicativo - expresión de la verdadera acción en el presente, pasado y futuro, el Subjuntivo - expresión de la acción de lo deseado, posible, probable en el pasado, presente y futuro), sino también la gama temporal de una acción que el modo 
Potencial (Condicional) no tiene. Basando en la definición del Condicional en el diccionario de términos lingüísticos, el autor sugiere que está relacionado con el modo Subjuntivo [Ibid., p. 36-37].

A. Anufriev, al considerar la categoría de modalidad, identifica una serie de enfoques con respecto al número de los modos en el español moderno. El científico cree que para la tradición española existen varios criterios de distinguir un modo en particular. En primer lugar, para asignar algún modo generalmente se utilizan criterios morfológicos y semánticos. Entonces, el modo Subjuntivo se desigualiza morfológicamente del modo Indicativo por las flexiones [5, p. 153].

Al mismo tiempo, el científico señala que A. Bello en su gramática está guiado principalmente por un criterio sintáctico. Para él, el modo es la forma que depende sintácticamente del predicado (el verbo tanto en la oración simple, como en la parte principal de la oración compuesta subordinada todavía tiene algún modus, que se deriva lógicamente y por lo tanto se puede distinguir diferentes modos). A. Bello asigna sólo dos modos: el modo Indicativo y el modo Subjuntivo (el Imperativo, según él, es la parte optativa relacionada con el modo Subjuntivo). El Indicativo es el modo para las oraciones principales. El modo Subjuntivo se caracteriza por una dependencia de los predicados de duda y deseo, es decir se entiende precisamente como el modo de subordinación. Resulta que un criterio sintáctico A. Bello todavía combina con el semántico, porque precisamente lo semántico de un modo define el modo dependiente [Ibid.].

Como resultado del análisis, A. Anufriev llega a la conclusión de que la mayoría de los científicos opinan, sin embargo, que el sistema de los modos españoles se basa en la oposición del Indicativo y Subjuntivo [5, p. 155].

Al mismo tiempo, según la RAE, en el español moderno hay tres modos: Indicativo, Subjuntivo e Imperativo. Esta afirmación nos permite en el marco de la investigación diferenciar los macrocampos del Indicativo, del Subjuntivo y del Imperativo respectivamente.

Sin duda, el interés especial en este contexto reside en el análisis del funcionamiento del macrocampo del Imperativo. Este macrocampo en la estructura campal de la lengua española se encuentra en la cruce de los campos del Indicativo y Subjuntivo.

Esta posición del Imperativo está condicionada por las formas de expresar su significación modal.

Toma el ejemplo de Dios y sé modesto como Él.

Papá, papá, ven aquí, necesito tu ayuda.

¡Venga conmigo, coronel Mejías!

¡Pónganse la mano al pecho!

Se pide cierta cultura general [7].

Las oraciones indican que la modalidad imperativa en el idioma español se puede expresarla tanto por las formas del Indicativo como por las del Subjuntivo.

Sin embargo, el Indicativo y el Subjuntivo representan la oposición de dos formas temporales con vívido contraste de la realidad y la imagen mental de suprarealidad, $<\ldots>$ no refleja la percepción real de la realidad aquí y ahora, como el resultado del pensamiento, sino un modelo alternativo de la realidad creado por la mente en el momento del habla [8].

Teniendo en cuenta la definición del Subjuntivo y el Condicional de N. Ivanov como los modos condicionalmente falso y condicionalmente cierto respectivamente, y el Imperativo como el modo que no tiene una función verdadera de la lengua, sino el que describe un hecho que deberá ocurrir, pero no ha sucedido en la realidad, creemos que desde un punto de vista pragmático el sistema de los tiempos españoles está representado por tres modos: Indicativo, Subjuntivo e Imperativo. Las formas del Condicional expresan solo ciertos matices modales que caracterizan los sistemas del Indicativo y Subjuntivo.

... podría tener una mano rota, necesitaré que se acerque hasta el hospital, y me traiga todo lo necesario para vendársela. (J. Navarro)

Pero antes le agradecería que se acercara a la tienda más cercana y comprara algo de ropa para Amelia. (J. Navarro)

¿Quién vendría conmigo?

Me agradaría mucho recibir noticias tuyas.

¿Tendría hambre, Lucas? [9].

El modo es una categoría gramatical que existe en el idioma para distinguir oraciones de tipos diferentes [5]. El Condicional en este sentido no puede ser considerado como un modo completo. Por lo tanto, surge la necesidad de asignarle un lugar determinado en la estructura campal que estamos construyendo.

Prestemos especial atención a la influencia de la semántica del Subjuntivo en esta forma temporal. Como resultado, aparece la distinta significación de modalidad. En las situaciones cuando las formas del Condicional funcionan en el contexto del sitema del Subjuntivo, la semántica del Subjuntivo sirve de "superestructura" en el diseño de alguna situación concebible en el discurso y caracteriza el hecho descrito con una mayor proporción de incertidumbre o duda. 
Para mi madre, sin ella nunca habría llegado hasta aquí. (J. Navarro)

Si me hubieras sobreprotegido habría sido peor.

Hacía tanto frío que la fogata se apagaría en cualquier momento [9].

Dado el carácter mencionado del Condicional lo consideremos como una zona semántica de los macrocampos tanto del Indicativo como del Subjuntivo.

Por lo tanto, teniendo en cuenta lo mencionado anteriormente, optamos por asignar una cierta estructura campal de lenguaje. En esta situación, basémonos en el modelo de la formación de los campos semánticos funcionales aprobado por N. Zenenko en el estudio de la dialéctica de dominantes estructurales a base del material de las lenguas de la Península Ibérica.

En este sentido, se formula una hipótesis, según la cual el campo de tiempo está representado por el núcleo que une las categorías semánticas funcionales de tiempo y de aspecto, que, al mismo tiempo, forman el campo semántico funcional de tiempo que después se transforma en el campo semántico funcional de modalidad.

Los campos semánticos funcionales de tiempo y de modalidad en el lenguaje corresponden a las categorías gramaticales de tiempo y de modalidad respectivamente.

Como el Condicional se considera ser una forma temporal que crea una zona semántica tanto en el modo Indicativo, como en el modo Subjuntivo, representando de esa manera respectivos significados conforme con el modo que resulta ser su base, concluimos que en el discurso el campo semántico funcional de tiempo y el campo semántico funcional de modalidad actúan como partes de un mismo proceso.

Por lo tanto, las ideas y las imágenes implicadas en los conceptos de nuestra mente forman categorías semánticas conceptuales que después se convierten en categorías semánticas funcionales en el lenguaje.

Dicho esquema nos ayuda a resolver la mayoría de los problemas que enfrentamos usando el idioma en la vida cotidiana. El estudio realizado contribuye a identificar el número total de los modos existentes en el español moderno.

\section{Literatura}

1. Ван Дейк Т. А. Язык. Познание. Коммуникация / Т. А. Ван Дейк: пер. с англ.; под ред. В. И. Герасимова; сост. В. В. Петрова ; вступ. ст. Ю. Н. Караулова, В. В. Петрова. Изд. 2-е. - М.: ЛЕНАНД, 2015. - 320 с.

2. Бочкова O. С. Категории модальности, времени и пространства в жанре научной фантастики: автореф. дис. ...канд. филол. наук : 10.02.19 / Бочкова Ольга Сергеевна. - Саратов, 2006. - 25 с.

3. Розенталь Д. Э. Словарь-справочник лингвистических терминов / Д. Э. Розенталь, М. А. Теленкова. 2-е изд. - М.: Просвещение, 1976. - 543 с.

4. Иванов Н. В. К логическим основаниям системы грамматических модальных значений в португальском языке // Структурная метафизика языка и феноменология речевого дискурса: критерии системных интерпретаций: материалы IX Межд. науч. конф. по актуальн. пробл. теории языка и коммуникации: сб. статей. - М.: Международные отношения, 2015. - С. 388-402.

5. Ануфриев A. А. Функционирование наклонений в придаточных предложениях, вводимых глаголами эпистемической оценки: на материале пиренейского варианта испанского языка: дис. ...канд. филол. наук: 10.02.05 / Ануфриев Александр Александрович. - М., 2011. - 307 с.

6. Зененко Н. В. Структурные доминанты языка. Функциональное поле предикативности и функциональное поле атрибутивности: на материале иберо-романских языков: монография / H. В. Зененко. М.: ИД «АТИСО», 2009. - 192 с.

7. Real academia española: Banco de datos (CREA) [en línea].Corpus de referencia del español actual. - Режим доступа: URL: http://www.rae.es

8. Дружинин A. C. Когнитивно-прагматические особенности контрафактивных грамматических конструкций в американском предвыборном дискурсе 2000-2012: автореф. дис. ...канд. филол. наук : 10.02.04 / Дружинин Андрей Сергеевич. - М., 2014. - 20 c.

9. Real academia española: Banco de datos (CREA) [en línea]. Corpus de referencia del español actual. - Режим доступа: URL: http://www.rae.es 